\title{
Comparison of induced sputum with bronchial wash, bronchoalveolar lavage and bronchial biopsies in COPD
}

\author{
S.R. Rutgers*, W. Timens**, H.F. Kaufmann***, Th.W. van der Mark*, G.H. Koëter*, D.S. Postma*
}

Comparison of induced sputum with bronchial wash, bronchoalveolar lavage and bronchial biopsies in COPD. S.R. Rutgers, W. Timens, H.F. Kauffman, Th.W. van der Mark, G.H. Koëter, D.S. Postma. C)ERS Journals Ltd 2000.

ABSTRACT: It is unclear how cellular and soluble inflammatory markers in induced sputum relate to markers in lavage fluid and biopsies in chronic obstructive pulmonary disease (COPD). This was investigated and also the possible differences between subjects with COPD and healthy controls assessed.

Eighteen nonatopic subjects with COPD and 11 healthy controls were studied. Sputum was induced by inhalation of hypertonic saline. The airways were lavaged, using the first $50 \mathrm{~mL}$ for bronchial wash (BW) and the subsequent $150 \mathrm{~mL}$ for bronchoalveolar lavage (BAL), and biopsies were taken from subsegmental carinae.

Neutrophils were the predominant cell type in sputum in COPD (median $77.3 \%$ ) but not in BW $(5.5 \%)$ and BAL fluid (1.7\%). Differential cell counts in sputum did not correlate with the counts in BW or BAL fluid or biopsies, whereas sputum eosinophil cationic protein (ECP) levels correlated with BW fluid ECP levels $(\rho=0.66, p=0.007)$ and sputum interleukin-8 (IL-8) concentration with BAL fluid IL-8 concentration ( $\rho=$ $0.52, p=0.026$ ). Subjects with COPD had a higher percentage of sputum neutrophils and eosinophils and higher concentrations of ECP and IL-8 than healthy controls. The higher percentages of eosinophils and concentrations of ECP were also seen in BW and BAL fluid. Finally, higher numbers of macrophages and eosinophils were found in biopsies.

In conclusion, induced sputum is derived from a different compartment from BW and BAL fluid and biopsies. Induced sputum may be useful for studying the contribution of luminal neutrophils and eosinophils in chronic obstructive pulmonary disease.

Eur Respir J 2000; 15: 109-115.
Depts of *Pulmonology, **Pathology and
***Allergology, University Hospital, Groningen, the Netherlands.

Correspondence: S.R. Rutgers

Dept of Pulmonology

University Hospital Groningen

P.O. Box 30.001

9700 RB Groningen

The Netherlands

Fax: 31503619320

Keywords: Biopsy

bronchoalveolar lavage

chronic obstructive pulmonary disease inflammation

sputum

Received: February 41999

Accepted after revision August 81999

This study was supported by the Stichting Astma Bestrijding and Astra Pharmaceutica, the Netherlands.
Inflammation of the airways is often present in chronic obstructive pulmonary disease (COPD) and consists of increased numbers of macrophages and lymphocytes in the airway wall and increased numbers of neutrophils in the airway lumen. Airway inflammation has been studied extensively in bronchial biopsy samples and bronchoalveolar lavage (BAL) fluid, but the invasiveness of bronchoscopy makes it less feasible for large-scale diagnostic and followup studies. Sputum induction has gained in interest as a tool for studying airway inflammation in COPD in recent years, since it is noninvasive, easily performed and well tolerated. Therefore, sputum induction might be an alternative to bronchoscopy for monitoring airway inflammation in COPD.

Neutrophils have been shown to be present in increased percentages in induced sputum in COPD and these percentages correlate negatively with the forced expiratory volume in one second (FEV1) [1]. The concentration of the neutrophil chemotactic cytokine interleukin-8 (IL-8) is also increased in induced sputum and highest in those with the highest percentages of neutrophils [1]. The neutrophil mediators myeloperoxidase and lipocalin and the eosinophil mediators eosinophil cationic protein (ECP) and eosinophil peroxidase have also been shown to be increased in induced sputum [2]. The latter two markers did not decrease after 2 weeks' treatment with inhaled or oral corticosteroids in a small number of patients with COPD [3].

It has not been established how inflammatory markers in induced sputum are related to markers in lavage fluid or biopsy samples in COPD. Analysing spontaneous sputum in seven stable chronic bronchitics, MAESTRELli et al. [4] found higher percentages of neutrophils and lower percentages of macrophages and lymphocytes than in BAL fluid. Sputum inflammatory cells percentages did not correlate with BAL fluid and biopsy sample cell percentages [4]. During an exacerbation, however, the percentages of sputum and BAL fluid eosinophils did correlate in patients with chronic bronchitis, whereas the percentages of sputum and biopsy sample eosinophils tended to correlate [4]. Studies performed in asthma showed variable correlations in eosinophil and neutrophil percentages between induced sputum and bronchial wash (BW) $[5,6]$ and BAL fluid $[4,7,8]$. Sputum eosinophil numbers tended to correlate with the number of eosinophils in bronchial biopsy samples in asthma [4, 7].

In order to investigate the application of induced sputum as an alternative to BAL and bronchial biopsies in research 
on COPD, the relationship of inflammatory markers in induced sputum with those in lavage fluid and biopsy samples in COPD was assessed. The cellular and biochemical constituents of induced sputum were compared with those of BW, and BAL fluid and bronchial biopsy samples from the same subjects. Furthermore, differences between subjects with COPD and matched healthy controls were compared.

\section{Methods}

\section{Subjects}

Subjects were recruited from the pulmonary outpatient clinic of the Groningen University Hospital and by advertisements in local newspapers. Twenty subjects with COPD, according to American Thoracic Society criteria [10], and 12 healthy control subjects participated in the study. Subjects with COPD had an FEV1 and an FEV1/ vital capacity of $<$ predicted value -1.64 residual SD [11] and an increase in FEV 1 of $<10 \%$ pred after inhalation of $1 \mathrm{mg}$ terbutaline via a Turbuhalerß. Four subjects with COPD were never smokers, all other subjects with COPD and the healthy controls were exsmokers. Exsmokers had quit smoking $\geq 1 \mathrm{yr}$ before the start of the study. Fourteen subjects with COPD had chronic bronchitis. All subjects had a negative history for asthma and atopy, a negative skin test result for 18 common aeroallergens (ALK, Groningen, the Netherlands) and negative results for specific serum immunoglobulin $\mathrm{E}$ for 11 common aeroallergens. Thirteen subjects who had received maintenance treatment with inhaled corticosteroids discontinued this $\geq 1$ month prior to the study. Exclusion criteria were treatment with oral corticosteroids and antibiotics or a respiratory tract infection in the month prior to the study. Healthy volunteers did not have a history of pulmonary disease and had normal lung function. The protocol was approved by the hospital ethical committee. All subjects gave their informed consent.

\section{Design}

The study involved three visits. At the first visit, history was taken, physical examination and spirometry with a reversibility test were performed and atopy was assessed. At the second visit, sputum was induced. At the third visit, 7-14 days after visit 2, bronchoscopy with bronchoalveolar lavage and bronchial mucosal biopsies was performed.

\section{Spirometry}

Spirometry was performed using a calibrated watersealed spirometer (Lode, Groningen, the Netherlands) according to standardized guidelines [11]. Subjects were asked not to use short-acting bronchodilators within $12 \mathrm{~h}$ before the measurements and not to smoke or drink tea or coffee on the morning of the visit.

\section{Sputum induction}

Sputum was induced via inhalation of a hypertonic saline aerosol, generated by an ultrasonic nebulizer (Ultraneb 2000; DeVilbiss, Somerset, PA, USA). The nebulizer was calibrated to an output of $1.5 \mathrm{~mL} \cdot \mathrm{min}^{-1}$ and produced particles with a diameter of $4.5 \mu \mathrm{m}$. Solutions of sodium chloride of 3, 4 and 5\% (weight/volume) were nebulized at room temperature $\left(20-22^{\circ} \mathrm{C}\right)$ for $7 \mathrm{~min}$ each, and administered through a $100-\mathrm{cm}$-long tube with an internal diameter of $22 \mathrm{~mm}$. Subjects had their nose clipped and held their mouth in front of the end of the tube, making exhalation beside the tube possible. Three FEV1 manoeuvres were performed $15 \mathrm{~min}$ after inhalation of $1 \mathrm{mg}$ terbutaline via a Turbuhaler $\mathbb{R}$ and the highest value taken as baseline FEV1. Subjects then inhaled the hypertonic saline aerosols for three periods of $7 \mathrm{~min}$. Following each period of hypertonic inhalation, subjects were asked to blow their nose and to rinse their mouth and gargle their throat thoroughly with water. They were then encouraged to cough and expectorate sputum into a sterile plastic container, which was kept on ice. The procedure was terminated after three periods of 7 min or after a fall in FEV1 of $\geq 20 \%$ from the baseline value.

\section{Sputum processing}

Sputum was processed within 15 min after termination of the induction. The volume of the whole sputum sample was determined, and an equal volume of $0.1 \%$ dithiothreitol (Sputolysin; Calbiochem, La Jolla, CA, USA) was added. The samples were agitated on a vortex mixer in a wide-bore plastic test tube and placed in a shaking water bath for $15 \mathrm{~min}$ at $37^{\circ} \mathrm{C}$ to ensure complete homogenization. The samples were then filtered through $48-\mu \mathrm{m}$ nylon gauze (Thompson, Ontario, Canada) and agitated on a vortex mixer. A total cell count (TCC) was performed on the filtered sample and viability was checked by means of trypan blue exclusion. The filtered sample was centrifuged for $5 \mathrm{~min}$ at $590 \times g$ at $4^{\circ} \mathrm{C}$. The supernatant was aspirated and stored in Eppendorf tubes at $-80^{\circ} \mathrm{C}$. The cell pellet was resuspended in fluorescence-activated cell sorter (FACS) buffer $(0.5 \%$ bovine serum albumin in phosphate-buffered saline $(\mathrm{pH} 7.4-7.6)$ ) to a concentration of $0.4 \times 10^{6}$ cells $\cdot \mathrm{mL}^{-1}$ and cytospins preparations were performed by putting $100 \mu \mathrm{L}$ of the cell suspension in the funnels and centrifuging for $5 \mathrm{~min}$ at $23 \times g$ with low deceleration. Two cytospin slides for differential cell counts were stained with May-Grünwald Giemsa (MGG). Differential cell counts were performed by counting 300 nonsquamous cells in each coded MGG cytospin preparation in a blinded fashion by two technicians. The mean of both scores was used for analysis. Absolute cell numbers per mililitre of sputum were calculated by multiplying the cell percentage by the total (nonsquamous) cell number in the sputum, divided by the volume of the sputum sample in mililitres.

\section{Bronchoscopy}

Subjects gargled with $5 \mathrm{~mL}$ of 2 or $4 \%$ lignocaine and had $2 \%$ lignocaine sprayed on the posterior pharynx and dripped on to the vocal cords. The flexible fibreoptic bronchoscope (Olympus B1 IT10; Olympus Optical, Tokyo, Japan) was introduced orally or nasally and wedged in a subsegmental bronchus of the middle lobe. Lavage was performed with four $50-\mathrm{mL}$ aliquots of normal saline prewarmed to $37^{\circ} \mathrm{C}$. Each aliquot was immediately recovered using a negative pressure of $<2.7 \mathrm{kPa} \quad(<20$ $\mathrm{mmHg}$ ). The first aliquot was recovered separately and labelled BW; the following three aliquots were pooled and 
labelled BAL. After completion of lavage, bronchial biopsy samples were taken from subsegmental carinae of the right or left lower lobe using cup forceps (Olympus BF21C; Olympus Optical).

\section{Lavage processing}

The BW and BAL fluid were placed on ice and processed within 10 min after recovery. The BW and BAL fluid were filtered through 48- $\mu$ m nylon gauze (Curapharm 249.1 filter; Maxxim Medical Europe, Den Barch, the Netherlands) and recovery and aspect were assessed. They were then centrifuged for $5 \mathrm{~min}$ at $400 \times g$ at $4^{\circ} \mathrm{C}$, and the supernatants were decanted and stored in Eppendorf tubes at $-80^{\circ} \mathrm{C}$. The cell pellet was resuspended in FACS buffer and centrifuged again for $5 \mathrm{~min}$ at $400 \times g$ at $4{ }^{\circ} \mathrm{C}$. The supernatant from the second centrifugation was aspirated and the cell pellet resuspended in FACS buffer for TCC determination, viability assessment and cytospin preparation (the cytospin centrifugation step was performed at $34 \times g$ ) (see Sputum processing). Cell counting, cytospin staining and expression of BW and BAL results were performed as for induced sputum.

\section{Biopsy sample processing and cell quantification}

The biopsy samples were embedded in Tissue Tek $\mathbb{R}$ optimal cutting temperature medium (Bayer Corporation, Elkhart, IN, USA), and snap-frozen in liquid isopentane. Samples were stored at $-80^{\circ} \mathrm{C}$ until further processing. Frozen biopsies were then cut serially, and divided into series of 19 sections (4- $\mu \mathrm{m}$ thick) and stored at $-20^{\circ} \mathrm{C}$ until use. Morphologically optimal tissue was selected on the basis of a haematoxylin and eosin-stained slide. Sections (4 $\mu \mathrm{m})$ were air-dried for $20 \mathrm{~min}$ and fixed in acetone for 10 min. Immunohistochemical staining was performed using monoclonal antibodies directed against the secreted form of ECP (EG2, 1:50; Sanbio, Uden, the Netherlands), neutrophil elastase (NP57, 1:40; Dako, Copenhagen, Denmark), CD3 (1:50; Becton-Dickinson, San Jose, CA, USA) and CD68 (1:500; Dako) for the detection of eosinophils, neutrophils, lymphocytes and macrophages respectively. Detection of the primary antibodies was performed using specific biotinylated rabbit antimouse immunoglobulins (1:300) and subsequently streptavidin conjugated to horseradish peroxidase (1:300), providing a reddish-brown product. Hydrogen peroxide $(1: 100)$ was used to block endogenous peroxidase and haematoxylin was used as counterstain. For each antibody, the total number of positively stained cells was counted to a depth of $100 \mu \mathrm{m}$ below a randomly selected $1-\mathrm{mm}^{2}$ area of epithelial basement membrane. Slides were coded and counted twice by one observer in a blinded fashion. The mean value was taken for analysis. Light microscopy was performed using a Zeiss microscope set at a magnification of $\times 200$ for EG2 and $\times 400$ for neutrophil elastase, CD3 and CD68.

\section{Biochemical assays}

The concentration of ECP in sputum supernatant and $\mathrm{BW}$ and BAL fluid was measured using the fluoroenzyme immunoassay (ImmunoCAP ECP, Pharmacia, Uppsala, Sweden). IL-8 was measured using a human IL-8 enzymelinked immunosorbent assay (ELISA) (Amersham, Little Chalfont, UK).

\section{Statistics}

Clinical characteristics are presented as mean \pm SD and cell characteristics as medians with ranges. Differences between subjects with COPD and healthy subjects were tested using the Mann-Whitney U-test and differences within groups using the Wilcoxon matched-pairs test. Correlation between cell variables were analysed using Spearman's rank correlation coefficient. Differential sputum cell counts (expressed as a percentage of nonsquamous cells) and absolute cell numbers in sputum (expressed in cells. $\mathrm{mL}^{-1}$ ) were used in the comparison of BW and BAL fluid, and absolute cell numbers were used in the comparison of inflammatory cell counts in induced sputum and bronchial biopsy samples. A p-value $<0.05$ was considered statistically significant. All analyses were performed using SPSS 6.0 for Windows (SPSS, Inc., Chicago, IL, USA).

\section{Results}

Two subjects with COPD did not yield sufficient fluid and biopsy sample for differential cell counting and were excluded from the analyses. One healthy subject was unwilling to undergo bronchoscopy. The clinical characteristics of the remaining 29 subjects are listed in table 1. Twelve subjects with COPD had received maintenance treatment with inhaled corticosteroids before the study. Nine subjects with COPD and one healthy subject yielded too little fluid or blood contamination of BW fluid, and two other subjects with COPD showed blood contamination of BAL fluid. Therefore, differential cell counts were not performed in BW or BAL fluid. One other subject with COPD had biopsy samples of too low a quality for cell counting.

Table 1. - Clinical characteristics of subjects

\begin{tabular}{lcc}
\hline & COPD & Control \\
\hline Sex M/F & $14 / 4$ & $8 / 3$ \\
Age yrs & $62 \pm 8$ & $58 \pm 8$ \\
Smoking pack-yrs & $28 \pm 22$ & $25 \pm 15$ \\
FEV1 \% pred & $59 \pm 13^{*}$ & $104 \pm 11$ \\
$\Delta$ FEV1 \% pred & $6 \pm 2$ & $3 \pm 3$ \\
Serum eosinophils cells·mL $\mathrm{mL}^{-1}$ & $170(30-540)$ & $91(13-430)$ \\
Total serum IgE U·mL & $30(2-282)$ & $17(2-88)$ \\
Sputum induction n & 18 & 11 \\
Bronchial wash n & 10 & 10 \\
Bronchoalveolar lavage n & 16 & 11 \\
Bronchial biopsy n & 17 & 10 \\
\hline
\end{tabular}

Data are presented as mean $\pm \mathrm{SD}$ or geometric mean (ranges). COPD: chronic obstructive pulmonary disease; M: male, F: female; FEV 1 : forced expiratory volume in one second; $\triangle \mathrm{FEV} 1$ : change in FEV1; IgE: immunoglobulin E. *: p<0.001, COPD versus healthy controls. 


\section{Within-group analysis}

Sputum versus bronchial wash fluid. In subjects with COPD, the percentage of neutrophils was higher and the percentage of nonsquamous epithelial cells was lower in sputum than in BW fluid (table 2). The TCC. $\mathrm{mL}^{-1}$ was higher in sputum than in BW fluid. Subjects who yielded low-quality cytospin preparations from BW fluid had a lower FEV1 (\% pred). They did not differ in other clinical variables nor in differential cell counts in sputum and BW and BAL fluid from those subjects with COPD who had adequate BW fluid cytospin preparations. In healthy subjects, the percentages of all inflammatory cell types except for macrophages were lower in sputum than in BW fluid. The TCC. $\mathrm{mL}^{-1}$ was higher in sputum than in BW fluid. The percentage and number of cells per millilitre of epithelial cells, macrophages, neutrophils, lymphocytes and eosinophils did not correlate between sputum and BW fluid in subjects with COPD nor in healthy subjects.

The concentrations of ECP and IL- 8 were higher in sputum than in BW fluid in both subjects with COPD and healthy subjects (table 3). Sputum and BW fluid ECP levels correlated in subjects with COPD $(\rho=0.66, p=$ $0.007)$ and in healthy subjects $(\rho=0.69, p=0.027)$. Sputum and BW fluid IL-8 levels did not correlate in subjects with COPD nor in healthy subjects.

Sputum versus bronchoalveolar lavage fluid. In subjects with COPD, the percentages of neutrophils and eosinophils were higher and the percentages of macrophages and lymphocytes were lower than in BAL fluid. The $\mathrm{TCC} \cdot \mathrm{mL}^{-1}$ was higher and the amount of fluid recovered was lower in sputum than in BAL fluid. In healthy subjects, the percentage of neutrophils was higher and the percentage of macrophages and lymphocytes lower in sputum than in BAL fluid. The TCC. $\mathrm{mL}^{-1}$ was higher and the amount of fluid recovered lower in sputum than in BAL fluid. The percentage and number of cells per millilitre of epithelial cells, macrophages, neutrophils, lymphocytes and eosinophils did not correlate between sputum and BAL fluid in subjects with COPD nor in healthy subjects.

The concentrations of ECP and IL-8 were higher in sputum than in BAL fluid in both subjects with COPD and healthy subjects. Sputum and BAL fluid ECP levels did not correlate in subjects with COPD nor in healthy subjects. Sputum and BAL fluid IL-8 levels correlated in subjects with $\operatorname{COPD}(\rho=0.52, p=0.026)$ but not in healthy subjects.

Sputum versus biopsy samples. The differential cell counts in sputum expressed in cells per millilitre and the differential cell counts in biopsy samples are shown in table 4. In subjects with COPD, neutrophils accounted for most of the cells in sputum, whereas macrophages and lymphocytes were the predominant inflammatory cell type in biopsy samples. In healthy subjects, macrophages and to a lesser extent neutrophils accounted for most of the cells, whereas macrophages, neutrophils and lymphocytes contributed almost equally to the inflammatory cells in biopsy samples. There were no correlations between sputum and biopsy samples for macrophages, neutrophils, and lymphocytes and between sputum eosinophils and activated eosinophils in biopsy samples in subjects with COPD nor in healthy subjects.

\section{Between-group analysis}

Sputum. Sputum fluid recovery and TCC $\cdot \mathrm{mL}^{-1}$ were significantly higher in subjects with COPD than in healthy subjects $(p=0.04$ and $p=0.03$, respectively). The sputum

Table 2. - Concentrations of cells in induced sputum and lavage fluid in subjects with chronic obstructive pulmonary disease (COPD) and healthy controls

\begin{tabular}{|c|c|c|c|c|c|c|}
\hline & \multirow[b]{2}{*}{ IS } & \multirow[b]{2}{*}{$\mathrm{BW}$} & \multirow[b]{2}{*}{ BAL } & \multicolumn{3}{|c|}{$\mathrm{p}$-value } \\
\hline & & & & IS/BW & IS/BAL & $\mathrm{BW} / \mathrm{BAL}$ \\
\hline \multicolumn{7}{|l|}{ COPD } \\
\hline Subjects $\mathrm{n}$ & 18 & 10 & 16 & & & \\
\hline Recovery mL & $9.6(2.7-24.2)$ & $8(3-14)$ & $61(15-98)$ & NS & 0.0007 & 0.0005 \\
\hline TCC $10^{6}$ cells $\cdot \mathrm{mL}^{-1}$ & $2.6(0.4-29.3)$ & $0.07(0.04-3.8)$ & $0.14(0.01-0.6)$ & 0.0004 & 0.0001 & 0.0299 \\
\hline Squamous cells \% & $5(0-12)$ & 0 & 0 & & & \\
\hline Nonsq epith \%* & $0.1(0-2.8)$ & $3.4(0-80.4)$ & $0.3(0-17.9)$ & 0.018 & NS & NS \\
\hline Macrophages \%* & $19.4(4.8-63.7)$ & $55.3(2.2-86.3)$ & $85.8(13.3-94.2)$ & NS & 0.0007 & 0.0109 \\
\hline Neutrophils \%* & $77.3(29.1-94.2)$ & $5.5(0.2-96.7)$ & $1.7(0.3-85.5)$ & 0.0173 & 0.0007 & 0.0251 \\
\hline Lymphocytes \%* & $1.9(0.7-6)$ & $3.5(0.8-18.9)$ & $6.9(1.2-30.4)$ & NS & 0.0007 & NS \\
\hline Eosinophils \%* & $1.2(0-8.5)$ & $0.5(0-2.1)$ & $0.4(0-1.7)$ & NS & 0.0038 & NS \\
\hline \multicolumn{7}{|l|}{ Controls } \\
\hline Subjects $n$ & 11 & 10 & 11 & & & \\
\hline Recovery mL & $5.7(3.9-16.3)$ & $10(5-18)$ & $85(36-110)$ & NS & 0.0033 & 0.0033 \\
\hline TCC $10^{6}$ cells $\cdot \mathrm{mL}^{-1}$ & $1.2(0.8-3.2)$ & $0.06(0.01-0.13)$ & $0.10(0.03-0.2)$ & 0.0051 & 0.0033 & 0.0069 \\
\hline Squamous cells \% & $6(3-14)$ & 0 & 0 & & & \\
\hline Nonsq epith \%* & $1.8(0.1-18.8)$ & $18.4(1.0-67.0)$ & $0(0-4.6)$ & 0.0069 & NS & 0.0051 \\
\hline Macrophages \%* & $57.3(34.2-76.7)$ & $72.0(26.9-96.5)$ & $92.0(70.4-96.5)$ & NS & 0.0033 & 0.0125 \\
\hline Neutrophils \%* & $35.7(17.6-59.7)$ & $3.4(0-25.2)$ & $1.1(0.1-3.0)$ & 0.0069 & 0.0033 & 0.0593 \\
\hline Lymphocytes \%* & $3.5(1-7.2)$ & $7.9(0.9-13.6)$ & $7.1(2.5-26.5)$ & 0.0284 & 0.0099 & 0.0745 \\
\hline Eosinophils \%* & $0.2(0-3.1)$ & $0(0-0.3)$ & $0.2(0-0.45)$ & 0.03 & NS & NS \\
\hline
\end{tabular}

*: of total nonsquamous cells. Data are presented as median (range). IS: induced sputum; BW: bronchial wash; BAL: bronchoalveolar lavage; TCC: total cell count; Nonsq epith: nonsquamous epithelial cell. 
Table 3. - Eosinophil cationic protein (ECP) and interleukin-8 (IL-8) concentration in induced sputum (IS) and bronchial wash (BW) and bronchoalveolar lavage (BAL) fluid

\begin{tabular}{|c|c|c|c|c|c|c|}
\hline & \multirow[b]{2}{*}{ IS } & \multirow[b]{2}{*}{ BW } & \multirow[b]{2}{*}{ BAL } & \multicolumn{3}{|c|}{ p-value } \\
\hline & & & & IS/BW & IS/BAL & $\mathrm{BW} / \mathrm{BAL}$ \\
\hline \multicolumn{7}{|l|}{ COPD } \\
\hline Subjects $n$ & 18 & 10 & 16 & & & \\
\hline ECP pg.mL $L^{-1}$ & $750(115-23760)^{\S}$ & $4(0-106)^{\#}$ & $0(0-62)^{+}$ & 0.0007 & 0.0002 & 0.0069 \\
\hline $\mathrm{IL}-8 \mathrm{ng} \cdot \mathrm{mL}^{-1}$ & $13.4(3.5-1300)^{3}$ & $0.16(0.11-6.7)$ & $0.040(0-2.6)$ & 0.001 & 0.0001 & 0.0092 \\
\hline \multicolumn{7}{|l|}{ Control } \\
\hline Subjects n & 11 & 10 & 11 & & & \\
\hline $\mathrm{ECP} \mathrm{pg} \cdot \mathrm{mL}^{-1}$ & $138(40-218)$ & $2(0-4)$ & $0(0-0)$ & 0.0051 & 0.0051 & 0.0277 \\
\hline $\mathrm{IL}-8 \mathrm{ng} \cdot \mathrm{mL}^{-1}$ & $4.6(3.1-7.7)$ & $0.10(0.05-0.5)$ & $0.008(0-0.06)$ & 0.0033 & 0.0033 & 0.0033 \\
\hline
\end{tabular}

Data are presented as median (range). COPD: chronic obstructive pulmonary disease. ${ }^{+}: \mathrm{p}=0.04{ }^{\#}: \mathrm{p}=0.01 ;{ }^{\dagger}: \mathrm{p}=0.0004 ;^{\S}: \mathrm{p}=0.0002$, COPD versus control.

percentages of neutrophils and eosinophils were significantly higher $(\mathrm{p}=0.0002$ and $\mathrm{p}=0.01$, respectively) and the percentages of epithelial cells, macrophages and lymphocytes were lower $(\mathrm{p}=0.004, \mathrm{p}=0.0001$ and $\mathrm{p}=$ 0.02 , respectively) in subjects with COPD than in healthy subjects. The percentages of macrophages was similar in subjects with COPD and healthy subjects. Sputum ECP and IL-8 concentrations were higher in subjects with COPD than in healthy subjects $(\mathrm{p}=0.0002$ and $\mathrm{p}=$ 0.0004 , respectively).

Bronchial wash and bronchoalveolar lavage fluid and biopsy samples. The percentages of eosinophils in BW and BAL fluid as well as the total number of eosinophils in BW fluid were higher in subjects with COPD than in healthy subjects $(\mathrm{p}=0.005, \mathrm{p}=0.03$ and $\mathrm{p}=0.01$, respectively). The percentages of macrophages was similar in BW and BAL fluid in subjects with COPD and in healthy subjects. BW and BAL fluid ECP concentrations were higher in COPD ( $\mathrm{p}=0.01$ and $\mathrm{p}=0.04$, respectively).

Table 4. - Numbers of inflammatory cells in induced sputum and bronchial biopsy samples

\begin{tabular}{|c|c|c|}
\hline & COPD & Control \\
\hline \multicolumn{3}{|l|}{ Induced sputum } \\
\hline Subjects & 18 & 11 \\
\hline $\begin{array}{l}\text { Nonsq epith } \\
10^{3} \text { cells } \cdot \mathrm{mL}^{-1}\end{array}$ & $0(0-2)$ & $15(3-432)$ \\
\hline $\begin{array}{l}\text { Macrophages } \\
10^{3} \text { cells } \cdot \mathrm{mL}^{-1}\end{array}$ & $632(4-140)$ & $646(293-1775)$ \\
\hline $\begin{array}{l}\text { Neutrophils } \\
10^{3} \text { cells } \cdot \mathrm{mL}^{-1}\end{array}$ & $1945(9-2744)^{\S}$ & $432(150-1240)$ \\
\hline $\begin{array}{l}\text { Lymphocytes } \\
10^{3} \text { cells } \cdot \mathrm{mL}^{-1}\end{array}$ & $47(8-291)$ & $43(14-91)$ \\
\hline $\begin{array}{l}\text { Eosinophils } \\
10^{3} \text { cells } \cdot \mathrm{mL}^{-1}\end{array}$ & $26(0-593)^{*}$ & $2(0-50)$ \\
\hline \multicolumn{3}{|l|}{ Biopsy samples } \\
\hline Subjects $n$ & 17 & 10 \\
\hline CD68 + cells $\cdot \mathrm{mm}^{-2}$ & $1155(330-2920)^{\nexists}$ & $\#$ \#90(450-1580) \\
\hline Neut elastase cells $\cdot \mathrm{mm}^{-2}$ & $385(10-1250)$ & $410(0-740)$ \\
\hline $\mathrm{CD} 3+$ cells $\cdot \mathrm{mm}^{-2}$ & $935(170-2240)$ & $385(210-1520)$ \\
\hline $\mathrm{EG} 2+$ cells $\cdot \mathrm{mm}^{-2}$ & $30(0-180)^{+}$ & $10(0-40)$ \\
\hline
\end{tabular}

Data are presented as median (range). COPD: chronic obstructive pulmonary disease; Nonsq epith: nonsquamous epithelial cell; EG2: secreted form of eosinophil cationic protein. ${ }^{+}$: $\mathrm{p}=0.049$; $^{\#}: \mathrm{p}=0.03{ }^{\star}: \mathrm{p}=0.01 ;^{\S}: \mathrm{p}=0.0015$, COPD versus control.
The numbers of CD68 and EG2-positive cells in biopsy samples were higher in COPD $(\mathrm{p}=0.03$ and $\mathrm{p}=0.049$, respectively), and the number of CD3 positive cells tended to be higher in COPD $(\mathrm{p}=0.065)$.

\section{Discussion}

It was found that the differential count of inflammatory cells in induced sputum did not correlate with differential cell counts in BW and BAL fluid nor biopsy samples, both in subjects with COPD and healthy controls. Sputum ECP concentrations correlated with BW fluid ECP concentrations and sputum IL-8 levels correlated with BAL fluid IL8 levels in subjects with COPD. Assessing the differences between patients with COPD and healthy subjects, higher percentages of sputum neutrophils and eosinophils and higher concentrations of sputum ECP and IL- 8 were observed in the COPD group. The higher percentage of eosinophils and concentration of ECP in the COPD group was also seen in BW and BAL fluid. Finally, higher numbers of macrophages and activated eosinophils were found in the biopsy samples of patients with COPD.

The lack of correlation between cell differentials in induced sputum and differentials in BW and BAL fluid suggests that sputum is derived from a different compartment in the lung. The gradient of percentage of neutrophils from sputum via BW fluid to BAL fluid and the reciprocal gradient of percentage of macrophages favours a collection site proximal to that of the $\mathrm{BW}$ fluid, i.e. in the large airways. The differences between induced sputum and lavage fluids are most probably not due to the technical differences of inhalation of hypertonic saline with sputum induction and instillation of normal saline with BAL. It has been shown previously that induced sputum does not have a significantly different cellular composition when compared with spontaneous sputum from subjects with COPD [12]. Moreover, another study showed that inhalation of hypertonic saline yielded more cells than inhalation of normal saline, yet with a similar differential count [13]. The differences in cellular counts between induced sputum and BW and BAL fluid, therefore, probably reflect differences between compartments in the lung.

Besides sampling in different compartments in the lung, the technique of sampling may also contribute to the lack of correlation of cell differentials between sputum and BAL fluid. Sputum can be regarded as a depository for 
cells and mediators with concentrations that do not change markedly over time [14]. BW and BAL can be regarded as a quick shower that gets whatever might be passing by, which may be dependent on the site lavaged and the amount of fluid used. This technique dependency makes possible correlations between BW and BAL fluid and induced sputum less strong.

In contrast to cell counts, the concentration of the soluble substances ECP and IL-8 in induced sputum correlated significantly and positively with those of lavage fluid. Apparently, these substances dissolve in the epithelial lining fluid and spread to different compartments in the lung more easily than luminal inflammatory cells. It is possible that analysis of soluble substances in induced sputum yields information on the inflammatory process over a larger area of the airways than does cell differential analysis.

The techniques that were used for studying airway inflammation sampled in different compartments and thereby provided insight into different aspects of airway inflammation in COPD. The choice of a specific technique should depend upon the aspect to be studied. Induced sputum may be useful for studying neutrophils and eosinophils in the large airways and soluble markers in the large airways and bronchoalveolar space. These inflammatory markers may be of little importance in chronic airflow limitation in COPD, which is determined by changes in the peripheral airways. A recent study of peripheral airways in surgical specimens revealed that increased numbers of CD8+ T-lymphocytes and increased smooth muscle area are associated with airflow limitation [15]. Studies on the association between findings in peripheral airways and inflammatory changes in induced sputum, BW and BAL fluid and biopsy samples would provide insight into the role of these latter techniques in the investigation of airflow limitation in COPD.

Several differences were found in inflammatory markers in the different compartments between subjects with COPD and healthy subjects. Since all subjects were free of exacerbations during the study, the differences were due to an ongoing inflammatory process in the airways in COPD, which persists despite smoking cessation. The main difference in airway secretions between subjects with COPD and healthy controls was the higher percentage of neutrophils in induced sputum. This difference was not observed in BW and BAL fluid and biopsy samples and suggests an accumulation of neutrophils in the large airways in COPD. The lack of increased numbers of neutrophils in bronchial biopsy samples in COPD may be due to rapid pulsed transbronchial migration of neutrophils, such that, at any timepoint, their numbers in tissues are low. Alternatively, this may be due to preferential accumulation of neutrophils within the epithelium or in interstitial lung tissue, sites not investigated in the present study.

Relatively low percentages of eosinophils were found in induced sputum and BW and BAL fluid and low numbers of activated eosinophils in biopsy samples in subjects with COPD, but these were significantly higher than in healthy controls in all compartments. Moreover, higher concentrations of the activation marker ECP were found in induced sputum in COPD. It is not clear whether these eosinophils are able to cause tissue damage.

Subjects with COPD had similar percentages of sputum and $\mathrm{BW}$ and BAL fluid macrophages but higher numbers of airway wall macrophages compared with healthy controls. It is unlikely that the different method of macrophage identification in biopsy samples, i.e. immunocytochemistry versus morphology in sputum and $\mathrm{BW}$ and $\mathrm{BAL}$ fluid, influenced the difference in airway wall macrophages between subjects with COPD and healthy controls.

This study explored the application of induced sputum as an alternative to bronchoalveolar lavage and bronchial biopsies in research on chronic obstructive pulmonary disease. It was concluded that the differential count of inflammatory cells in induced sputum does not correlate with findings in bronchial wash and bronchoalveolar lavage fluid or biopsy samples in subjects with chronic obstructive pulmonary disease and healthy controls, whereas soluble markers do correlate. This suggests that induced sputum is derived from a different compartment from bronchial wash and bronchoalveolar lavage fluid and biopsy samples. Based on the present observations, the authors put forward that the compartment from which sputum is derived consists of the large airways. Subjects with chronic obstructive pulmonary disease had higher percentages of neutrophils and to a small extent more eosinophils than healthy controls. This was consistently observed in bronchial wash and bronchoalveolar lavage fluid and biopsy samples for eosinophils only. The authors suggest that induced sputum may be a useful tool for studying the priming and activity of neutrophils and eosinophils in chronic obstructive pulmonary disease. Furthermore, soluble markers in induced sputum may provide information about inflammation in the large airways and bronchoalveolar space.

Acknowledgements. The authors thank N. Tzanakis and $\mathrm{N}$. ten Hacken for their help with the bronchoscopy; A. Timmermans and J. Noordhoek for the processing and counting of the sputum and lavage fluid specimens and the measurement of interleukin-8 and eosinophil cationic protein concentrations; and B. Rutgers and M. Lodewijk for the cutting and staining of the biopsy samples.

\section{References}

1. Keatings VM, Collins PD, Scott DM, Barnes PJ. Differences in interleukin-8 and tumor necrosis factor-alpha in induced sputum from patients with chronic obstructive pulmonary disease or asthma. Am J Respir Crit Care Med 1996; 153: 530-534.

2. Keatings VM, Barnes PJ. Granulocyte activation markers in induced sputum: comparison between chronic obstructive pulmonary disease, asthma, and normal subjects. $\mathrm{Am}$ J Respir Crit Care Med 1997; 155: 449-453.

3. Keatings V, Jatakanon A, Miin Worsdell Y, Barnes PJ. Effects of inhaled and oral glucocorticoids on inflammatory indices in asthma and COPD. Am J Respir Crit Care Med 1997; 155: 542-548.

4. Maestrelli P, Saetta M, Di Stefano A, et al. Comparison of leukocyte counts in sputum, bronchial biopsies, and bronchoalveolar lavage. Am J Respir Crit Care Med 1995; 152: 1926-1931.

5. Fahy JV, Wong H, Liu J, Boushey HA. Comparison of samples collected by sputum induction and bronchoscopy from asthmatic and healthy subjects. Am J Respir Crit Care Med 1995; 152: 53-58. 
6. Keatings VM, Evans DJ, O'Connor BJ, Barnes PJ. Cellular profiles in asthmatic airways: a comparison of induced sputum bronchial washings, and bronchoalveolar lavage fluid. Thorax 1997; 52: 372-374.

7. Grootendorst DC, Sont JK, Willems LNA, et al. Comparison of inflammatory cell counts in asthma: induced sputum versus bronchoalveolar lavage and bronchial biopsies. Clin Exp Allergy 1997; 27: 769-779.

8. Pizzichini E, Pizzichini MMM, Kidney JC, et al. Induced sputum, bronchoalveolar lavage and blood from mild asthmatics: inflammatory cells, lymphocyte subsets and soluble markers compared. Eur Respir J 1998; 11: 828-834.

9. Lensmar C, Elmberger G, Sandgren P, Skold CM, Eklund A. Leukocyte counts and macrophage phenotypes in induced sputum and bronchoalveolar lavage fluid from normal subjects. Eur Respir J 1998; 12: 595-600.

10. American Thoracic Society. Standards for the diagnosis and care of patients with chronic obstructive pulmonary disease (COPD) and asthma. Am Rev Respir Dis 1987; 136: $225-244$.
11. Quanjer PH, Tammeling GJ, Cotes JE, Pedersen OF, Peslin R, Yernault JC. Lung volumes and forced ventilatory flows. Eur Respir J 1993; 6: 5-40.

12. Bhowmik A, Seemungal TAR, Sapsford RJ, Devalia JL, Wedzicha JA. Comparison of spontaneous and induced sputum for investigation of airway inflammation in chronic obstructive pulmonary disease. Thorax 1998; 53: 953-956.

13. Bacci E, Cianchetti S, Paggiaro PL, et al. Comparison between hypertonic and isotonic saline-induced sputum in the evaluation of airway inflammation in subjects with moderate asthma. Clin Exp Allergy 1996; 26: 1395-1400.

14. Pizzichini E, Pizzichini MMM, Efthimiadis A, et al. Indices of airway inflammation in induced sputum: reproducibility and validity of cell and fluid-phase measurements. Am J Respir Crit Care Med 1996; 154: 308-317.

15. Saetta M, Di Stefano A, Turato G, et al. CD8+ T-lymphocytes in peripheral airways of smokers with chronic obstructive pulmonary disease. Am J Respir Crit Care Med 1998; 157: 822-826. 